Daniel GómezValcárcel Gómez

Figura 1. El McCormick Tribune Campus Center desde el SO. Autor desconocido. Fecha desconocida. Ref. web 1 .

Figura 2. La durée poignardée. Magritte, René. 1938. Ref. web 2 .
Arquitecto. Programa de Doctorado

en Proyectos Arquitectónicos Avanzados.

Escuela Técnica Superior de Arquitectura de Madrid.

Universidad Politécnica de Madrid.

\title{
Biuer... Chicago! Un argumento surrealista para el
McCormick Tribune Campus Center
}

Keywords: Koolhaas, McCormick, Surrealism, Pop.

Under its casual and colorful appearance, the McCormick Tribune Campus Center built in 2003 at the Chicago IIT campus by Rem Koolhaas constitutes a perplexing -hard to grasp conceptually-architectural piece. The commission origin was an international competition whose bases demanded a building "equal in stature to Mies van der Rohe's S. R. Crown Hall" that "will express the architecture of our time". According to Koolhaas, the building, in which he subverts all kind of disciplinary categories that shape Mies's work, is a built response to the condition of our time described in Junkspace, a text written in parallel to its construction proccess. The article argues that a surreal halo shines under its pop aesthetic. Being its significance reinforced by Koolhaas' clear appreciation of the findings of the Surrealists -among whom, especially, Dali's paranoid-critical method-, it may constitute a clue of deeper arguments that, steeping the strategy and methodology of the project, contribute to articulate the construct with which its author gives response to the competition intellectual demands.

\section{Chicago, fin de siglo}

El McCormick Tribune Campus Center de Rem Koolhaas irrumpe en 2003 en el orden abstracto que Mies van der Rohe impuso en el trazado del campus del Illinois Institute of Technology. Entre los perfiles anodinos de los edificios universitarios, el enorme tubo que lo aplasta dialoga con las cuatro grandes vigas peraltadas que soportan la cubierta del Crown Hall, obra maestra de Mies situada a escasos doscientos metros y con la que -según las bases del concurso que dio origen al encargo- debía medirse.

$\mathrm{El}$ escorzo de la figura 1 se convirtió en icono identificador del edificio desde su terminación. Pero sobre la evidente utilización de recursos pop-los cerramientos coloreados, el brillante tubo estriado, los iconos y rótulos que lo puntúan, el uso de materiales vulgares- predomina el halo surreal de la situación. El protagonismo del tren emergente remite a otro tipo de figuración y evoca una conocida propuesta surrealista imaginada por René
Magritte "en un momento de lucidez" y fijada en su lienzo La durée poignardée, expuesto en el Art Institute de Chicago.

En junio del 97, Koolhaas fue invitado a participar en el concurso para un centro de estudiantes: "El nuevo edificio proveerá el punto focal del renovado campus del IIT (...) y expresará la arquitectura de nuestro tiempo". El documento de Procedimientos de la convocatoria señala: "Imaginamos un edificio de la talla del Crown Hall (...) que extienda sus valores para hacerlos relevantes en el próximo siglo". ${ }^{1}$

En su Letter of interest, Koolhaas califica la oportunidad como "un programa excepcional que inevitablemente jugará un papel polémico e ideológico en el último tramo del siglo XX y el principio del XXI". ${ }^{2}$ Propone al efecto una obra construida y -al modo de Duchampun manual de interpretación, Junkspace (El espacio basura): dos formatos complementarios para un discurso que presenta elementos calificables de surrealistas, como podría

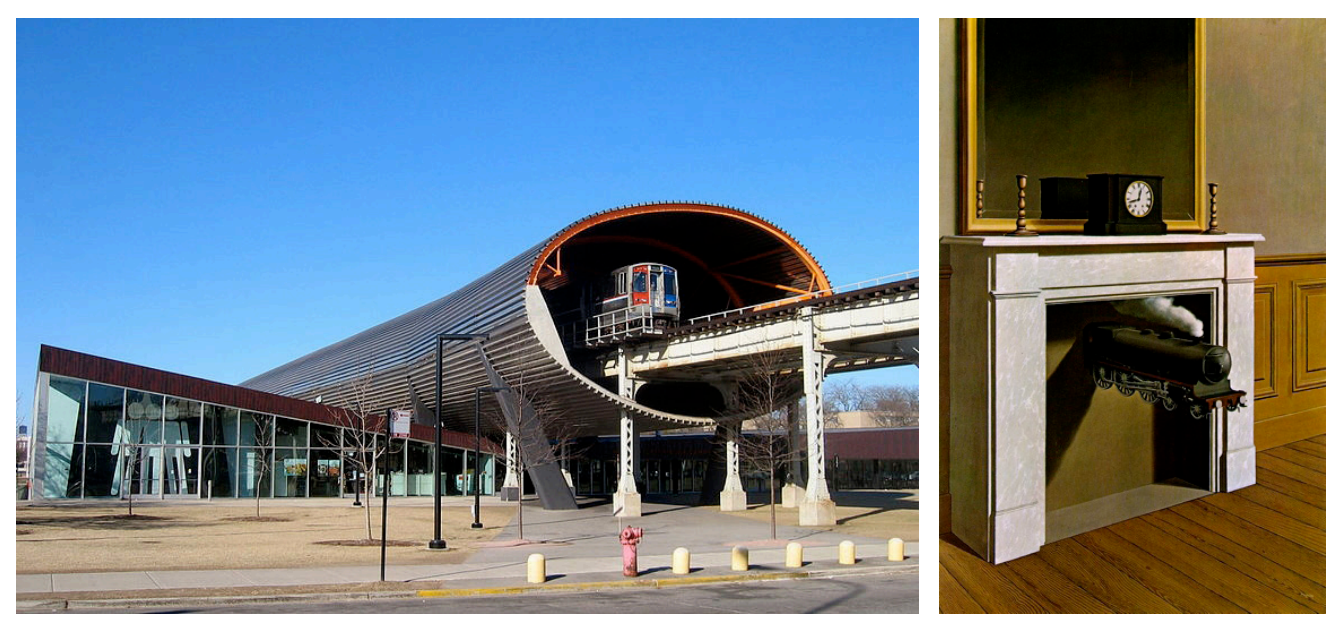


corresponder a la irracionalidad del tiempo histórico que describe en las 7000 palabras de su panfleto. En un lenguaje incisivo y vehemente se enumeran sintomas de una situación ominosa en que la producción arquitectónica se ha contraído y enfocado "sobre un único programa" bajo la presión del mercado, ya globalizado:

La modernización tenía un programa racional: compartir universalmente las bendiciones de la ciencia. El espacio basura es su apoteosis, o su derretimiento; aunque cada una de sus partes es fruto de brillantes inventos, su suma augura el final de la Ilustración, su resurrección como una farsa, un purgatorio de poca calidad. (Koolhaas 2000: 23)

En correspondencia con el sindrome descrito en Junkspace, el McCormick se nos muestra como un "mosaico sin suturas de lo permanentemente inconexo", un conjunto heteróclito de elementos de diversos órdenes, desplegados en una geometría planimétrica desvinculada de patrones reconocibles y altimétricamente confinado en una sección libre que discurre entre planos flexionados, fragmentados y fracturados, y cuyos elementos de diferente naturaleza son soportados por familias estructurales correspondientes.

El presente texto argumenta que, atendiendo a la configuración del edificio, a la trayectoria profesional e intelectual de su autor y a las alusiones directas por su parte, los objetivos, prácticas, métodos y conceptos de los surrealistas pueden ofrecer claves de interpretación útiles para mejorar las condiciones de comprensión de este proyecto difícilmente aprehensible bajo categorias estrictamente disciplinares.

\section{Pop... incluso}

En una entrevista celebrada tras la terminación del edificio, Koolhaas sitúa su trabajo en una linea histórica argumental que, partiendo tras la Segunda Guerra Mundial, relacionaria arquitectura y capitalismo y cuyos dos primeros protagonistas serian Mies van der Rohe y Robert Venturi. (Becker 2003)

No es la única referencia a Venturi en relación con el McCormick. Los conceptos destilados por él, Scott-Brown y su equipo en el análisis de la arquitectura y el urbanismo existentes en el Strip de Las Vegas en 1972 encuentran una jovial trasposición al mundo de lo construido en la primera obra americana de Koolhaas. Tributo inconsciente o voluntario, la mirada de Venturi sobre el orden inclusivo y dificil, el emplazamiento de los edificios, su carácter de mera infraestructura tras un cartel anunciador (en nuestro caso sería el tubo que encapsula la vía del tren), la coexistencia de estratos significativos en palimpsestos (Venturi alude al Foro romano; Koolhaas lo hace, como veremos, a un "tapiz pompeyano"), a la noción de "nueva monumentalidad", las relaciones entre espacios públicos y privados y otros conceptos emergen en un análisis detallado del McCormick. Como ejemplo significativo, Koolhaas reprocha a sus rivales en el concurso sus propuestas "únicas y heroicas" que ignoran los valores de lo genérico desarrollados por Mies en el campus del IIT. Estos términos, aplicados por Venturi al valor simbólico de los edificios de arquitectura culta, son confrontados en Aprendiendo de las Vegas a los de "feo y ordinario" aplicables a los edificios del Strip y de los que propone un uso voluntario y consciente, ya sea complementario o alternativo al "único y heroico", en la producción arquitectónica. Algunos de estos atributos son compartidos con las piezas vinculadas al Pop Art, como el uso del color y de la iconografía, el recurso a materiales vulgares, el tratamiento brillante y estriado del tubo; o la gráfica de difusión del proyecto. ${ }^{3}$

La filiación pop del McCormick sería, por tanto, oportuna; pero también contribuye a contextualizar el proyecto. Norteamérica debe a este movimiento su posición dominante en el mercado mundial del arte en los años sesenta. Para Richard Hamilton, ${ }^{4}$ el Pop Art "debe ser popular, efimero, desechable, de bajo costo, de producción masiva, joven, ingenioso, sexy, efectista, glamuroso y un gran negocio". La retórica desenfadada de su versión más reconocible, familiar a la sociedad de masas por una relación recíproca con el lenguaje publicitario, se presume apropiada para el alumnado proveniente de los cinco continentes al que se dirige la operación de puesta al día del "campus más feo de América" ${ }^{5}$ que dio origen al concurso.

Sin embargo, el análisis de los recursos pop utilizados en el McCormick no permite la aprehensión intelectual de este extraño edificio. Frente a la orientación dialéctica, esencialista y excluyente de Mies que ordena el campus y configura el Crown Hall, el aparente caos que representa el edificio demanda una conceptualización de otra naturaleza. Existen suficientes indicios para orientar la búsqueda de argumentos en el campo surrealista, cuya influencia en la obra de Koolhaas ya ha sido tratada por autores como Roberto Gargiani (2008:15) y señalada por sus pares. 

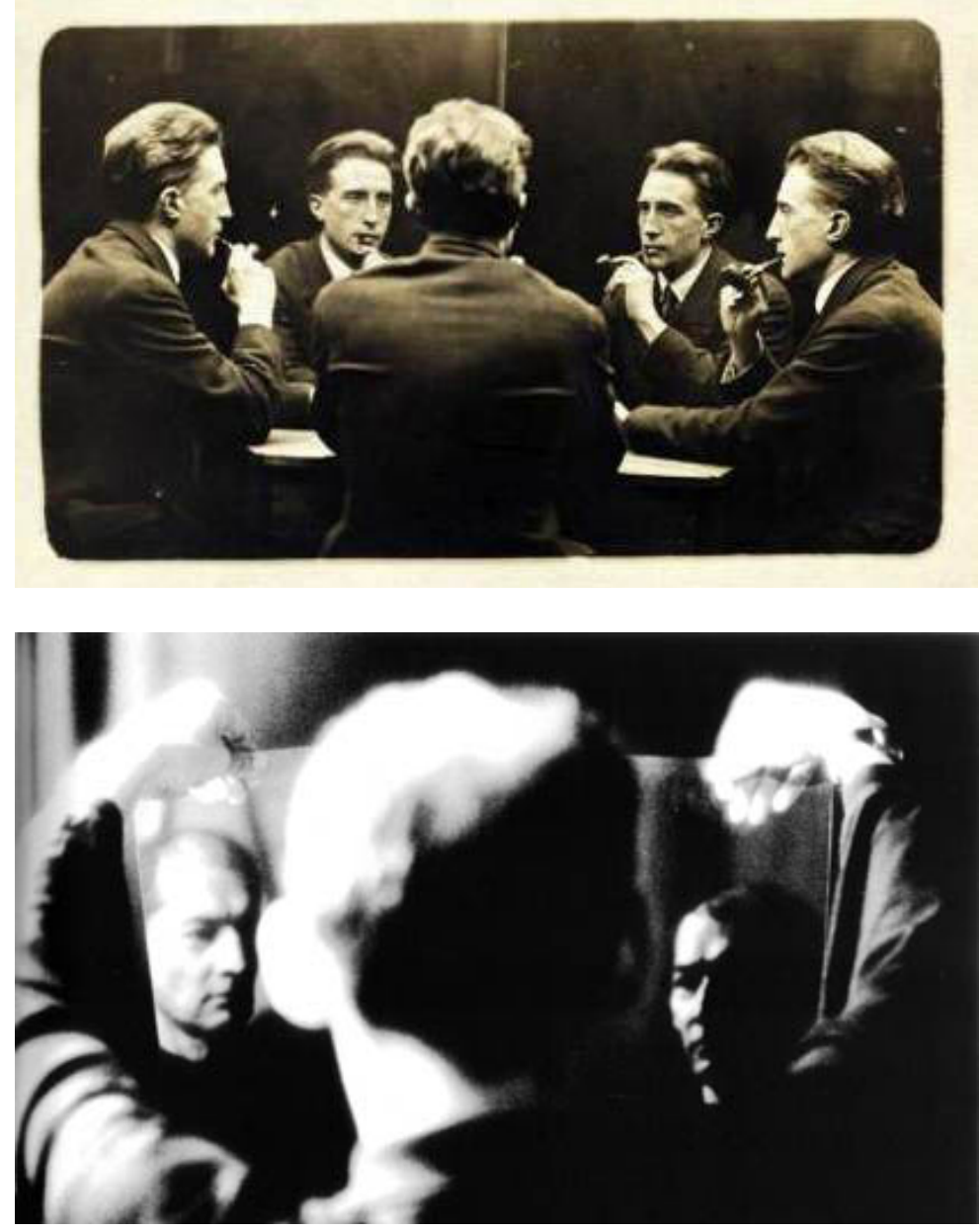

Figura 3. Retrato de Marcel Duchamp en el Broadway Photo Shop, NY. Autor desconocido. 1917. Ref. web 03.

Figura 4. Retrato de Rem Koolhaas. Autor desconocido. Fecha desconocida. El Croquis 53+79, 1998: 11
El primero se refiere a un juicio entre pares, y nos hace retroceder algo más de una década desde la convocatoria del concurso.

\section{Con otros ojos}

En Chicago, en 1986, Peter Eisenman categoriza el trabajo de Koolhaas como surrealista. La conversación gira en torno al (entonces) proyecto de la Villa dall'Ava. Koolhaas lo niega -"no creo que haya un propósito surrealista en absoluto"- (Eisenman 1987: 6566), ${ }^{6}$ pero años después Rafael Moneo ilustra la capacidad de Koolhaas para estimular la percepción de la realidad a través de su arquitectura cuando escribe acerca de la Villa dall'Ava: "infinita secuencia de espacios y sensaciones" que hace que la casa "se convierte en marco desde el que 'mirar con otros ojos' el mundo". (Moneo 2004: 350-351). Y el propio Koolhaas, en 1995, recupera esta observación -en la cita elude su propio rechazo- para incluirla textualmente bajo la voz "SURREAL" del Diccionario que recorre $S, M, L, X L$. Le sigue la voz "SURREALISM", donde transcribe una respuesta a Alejandro Zaera:

El surrealismo es una corriente que me interesa desde hace tiempo, más por su ca- pacidad analitica y su explotación del subconsciente que por su estética... Estaba más influido por sus métodos paranoicos, que considero una de las invenciones más genuinas de este siglo: un método racional que no pretende ser objetivo, a través del cual el análisis se identifica con la creación. (Koolhaas 1995: 1190)

Es patente la familiaridad de Koolhaas con los objetivos, el imaginario, los métodos, las prácticas y las actividades de los surrealistas. Delirious New York constituye una buena prueba de ello; tanto en su primera parte, analítica, como en su parte final propositiva. Y, por otra parte, el capítulo dedicado a Salvador Dalí y su "método paranoico-crítico" fue publicado previamente -bajo el título "Biuer! Ai bring ou surrealism. Aulredi meni pipoul in Niu York jove bin infected bai zi laifquiving and marvelous sors of surrealism!"- en un número doble monográfico de Architectural Design dedicado a la relación entre arquitectura y surrealismo, editado por Dalibor Vesely durante los primeros meses de 1978 (AD Profiles 11, 3-4 1978). ${ }^{7}$ Incluía dos textos antiguos sobre arquitectura y sobre Gaudi de Salvador Dalí -cuyo lienzo Ruinas atávicas tras la lluvia ocupa la portada. Entre las imágenes incluidas destaca, por su duplicidad, la contraportada: una Torre de Babel, de origen no identificado, a página completa, que encuentra su doble en una interpretación de1679 de Athanasius Kircher que ilustra el artículo Ciudades fantásticas de Peter Inch (1978)

En el interior del número, temas, prácticas y técnicas de los surrealistas son analizados y sistematizados desde diferentes posiciones por una decena de autores, entre los que se encontraban el propio Vesely, Bernard Tschumi o Kenneth Frampton. Temas como la ciudad -interpretada como sueño, como aventura amorosa, como palimpsesto histórico, como texto poético, como laberinto psíquico o como sistema de signos- el salón burgués, lo inquietante agazapado en los objetos familiares, cuyos aspectos cristalizaban en conceptos como objeto surrealista o belleza convulsiva, y eran tratados y materializados mediante diversas técnicas: el ready-made, la invención de lo inútil, el Merzbau de Schwitters, los collages y assemblages, el cadáver exquisito, los automatismos, las decalcomanías sin objeto preconcebido, el frottage o el -elogiado por Koolhaas, como queda dicho"método paranoico-crítico". 

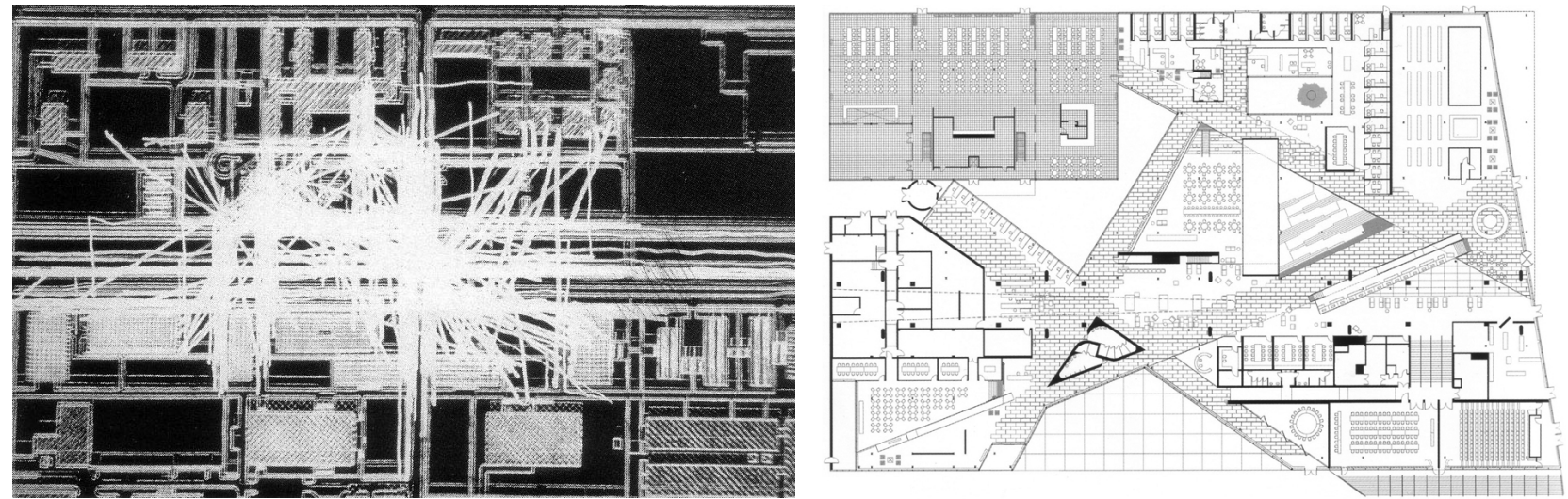

En 1992, en una entrevista con Alejandro Zaera, Koolhaas insiste en expresiones como "estado artificial de inconsciencia", "incertidumbre", "inexplicable refinamiento y misterio", "aproximación subconsciente", "perturbación" (Zaera 1991: 21). Pero, respecto a la estética asociada a esta forma de sensibilidad, aunque manifiesta un significativo desdén, sobre el que volveremos más adelante, que ilumina el paralelismo existente entre los (auto)retratos mostrados, y que se corresponde con la voluntad de conceptualización de la obra compartida con Duchamp. De Koolhaas conocemos su interés en utilizar de forma consciente la práctica arquitectónica como expresión de pensamiento: "yo soy un pensador", "no hay detalle, sólo puro concepto" (Zaera 1991: 18) que sintonizan con el desapego de Marcel Duchamp por el arte retiniano: "Quería alejarme del aspecto físico del cuadro. Me interesaba mucho más recrear ideas al pintar. El título era para mí muy importante". 8

\section{La mesa de disección}

Este aprecio genérico por la dimensión irracional de la experiencia desvelada por los surrealistas es concretado por Koolhaas en su toma de posición frente al proyecto de McCormick.

"El encuentro entre la solitaria caja de Mies y el paso de los trenes elevados como cohetes es tan absurdo como el encuentro de Lautréamont entre el paraguas y la máquina de coser" (Koolhaas 2001: 182). Así categoriza Koolhaas, en Miestakes, la condición física del campus. Se refiere a la (aparentemente) imposible relación entre el Commons Building, último edificio diseñado por Mies en el campus, y "el paso" de los trenes. En esta alusión emerge un tono de conceptualización del proyecto cercano a principios surrealistas, que refuerza la categorización señalada por Eisenman en 1988. Y ello a pesar del as- pecto pop... o quizá a través de componentes surrealistas integrados en las bases conceptuales de esta corriente artística. Porque ya en 1966, en pleno auge del Pop Art, el crítico de arte David Irwin rechaza la pertinencia de la etiqueta bajo la que fueron denominados sus artistas, "New Realists", y argumenta que obras de Rauschenberg, Johns, Dine, Oldenburg, Segal, Raysse o Watts tenían raíces en conceptos surrealistas. Incluso los artistas que encarnan la idea arquetípica de Pop Art -como Warhol, Oldenburg o Lichtenstein-, que no representan a todos los agrupados bajo la categoría, trabajarían, según Irwin, planteando un fondo de extrañamiento de filiación surrealista a objetos familiares y superponiendo un tema o lenguaje publicitario. Este lenguaje produciria, por su familiaridad con el espectador, la equívoca ilusión de realismo. En otros casos, la dimensión surrealista no es ni siquiera velada por el lenguaje plástico informal, colorista e intrascendente que identificamos con la estética Pop. Así, los trabajos de Kienholz o Wesselman y los happenings de Oldenburg (Irwin 1966). En una hipotética orientación surrealista de esta obra de Koolhaas se podría, por tanto, argumentar la latencia surreal del lenguaje pop.

Pero, reciprocamente, como veremos, los recursos pop pueden asumir la función legitimadora del delirio paranoico que Dalí asigna, en sus piezas pictóricas, a su apropiación de la técnica realista de los grandes maestros en la aplicación de su "método paranoico-crítico".

\section{E1 método}

Dalí pretende, con su método paranoico-crítico, convertir en productivo el proceso de enajenación atribuido a la paranoia como desorden mental. Es un procedimiento en dos fases, consecutivas pero diferenciadas, consistentes en enunciar un postulado -siempre arbitrario, generalmente
Figura 5. "Líneas de deseo", itinerarios de los alumnos del IIT en el solar. OMA. Fecha desconocida. El Croquis $131+132,2006$ : 339.

Figura 6. McCormick Tribune Campus Center, planta. OMA. Fecha desconocida. El Croquis $131+132$ 2006: 346. 
Figura 7. "Sistemas" de desarrollo conceptual del proyecto en la fase de concurso OMA. 1998. OMA, documentos originales de desarrollo de proyecto.

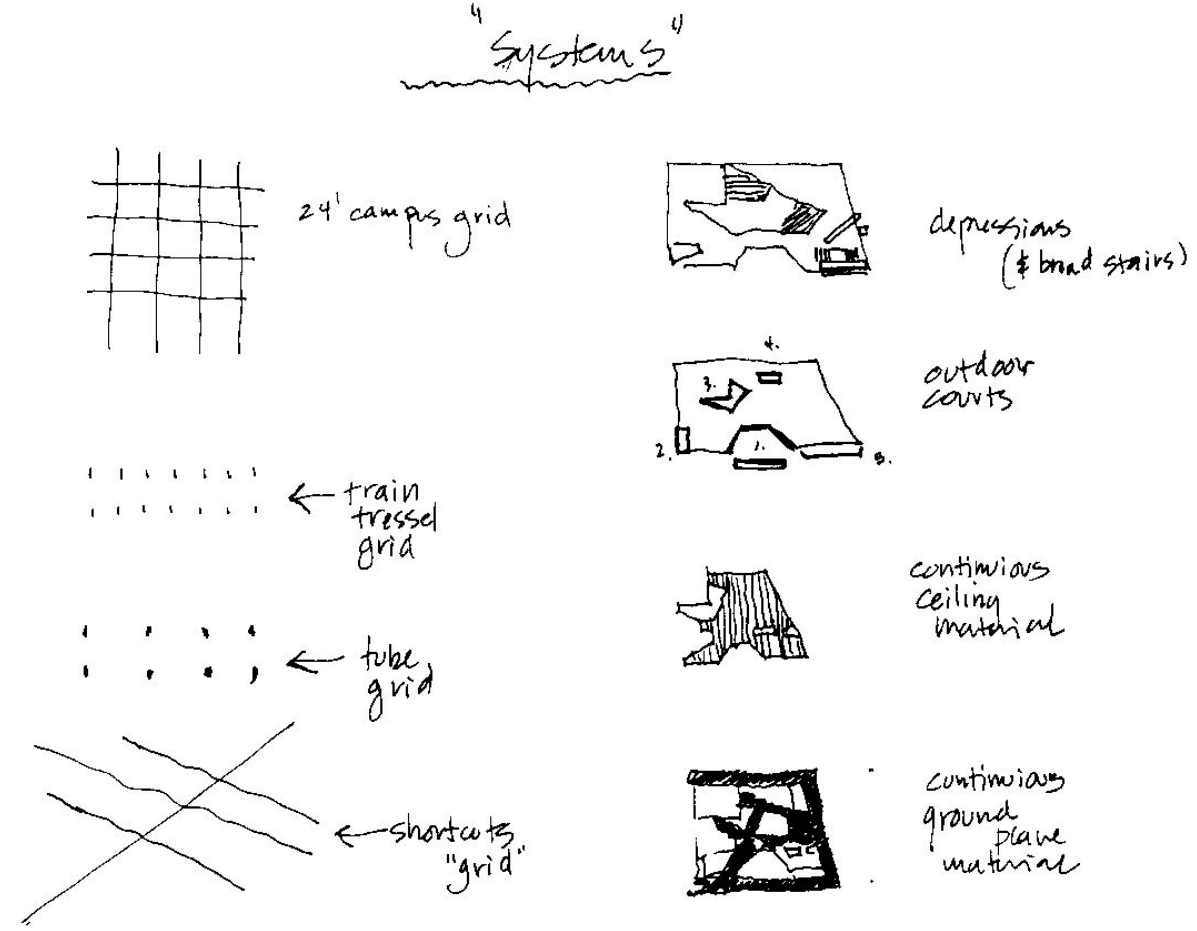

subjetivo, a veces delirante, homologable en su carencia de anclaje en la realidad fáctica a los generados por estos enfermos; proveniente de un sueño, pongamos por ejemplo- y convertirlo en un hecho material -de naturaleza artística, en principio- mediante la aplicación de recursos y técnicas objetivas. El propio André Breton califica el método como un instrumento de primerísimo orden para el surrealismo, destacando la capacidad de su autor para aplicarlo "indiferentemente a la pintura, a la poesia, al cine, a la construcción de objetos surrealistas típicos, a la moda, a la escultura, a la historia del arte ...".(Dalí 1971: 13)

Como ha señalado Juan Antonio Ramírez (1996: 301), en el método paranoico-crítico la voluntad consciente y racional no intenta corregir la visión paranoica, sino imponerla al mundo, materializarla. Se trata de una exaltación de los fantasmas y de los mecanismos sustitutorios del inconsciente en la que la mente analitica interviene, más que para elucidarlos (objetivo del psicoanálisis, sobre cuyos mecanismos se apoya), para representarlos. Y, para ello, Dalí no elude la mención a recursos concretos:

El ilusionismo del arte imitativo más abyectamente arribista e irresistible, los hábiles trucos del trome l'oeil paralizante, el academicismo más analiticamente narrativo y desacreditado, pueden convertirse en jerarquías sublimes del pensamiento al acercarse a las nuevas exactitudes de la irracionalidad concreta, a medida que las imágenes de la irracionalidad concreta se aproximan a la realidad fenoménica, y los medios de expresión correspondientes se acercan a los de la gran pintura realista-Velázquez y Vermeer de Delft ... (Dalí 1971: 21)

Dicho en otras palabras, la verosimilitud legitimadora del delirio representado se confia al grado de realismo de la técnica de representación. Cabe preguntarse, en una hipotética trasposición del método paranoico-crítico al mundo construido de la arquitectura, que recursos sustituirian a las técnicas realistas de una práctica de representación como la pintura. Aunque éste es un tema susceptible de desarrollo en otra instancia, cabe apuntar que el "realismo" que impone el McCormick se apoya en la intensificación de su materialidad.

Pero la interpretación de la obra pictórica de Dalí, y sus dobles o triples lecturas -basadas, en sus registros más inmediatos, en efectos visuales como la relación figura-fondo-, requieren la información, complicidad y participación activa del espectador. En este juego el autor dispone los elementos, pero pierde el control de lo interpretado por aquél: "toda explicación surge, pues, a posteriori, una vez que el cuadro existe ya como fenómeno." (Dali 1971: 20)

Dalí insiste en la importancia, como factor de utilidad para la producción artística, del carácter sistemático de la estructura del delirio paranoico: 

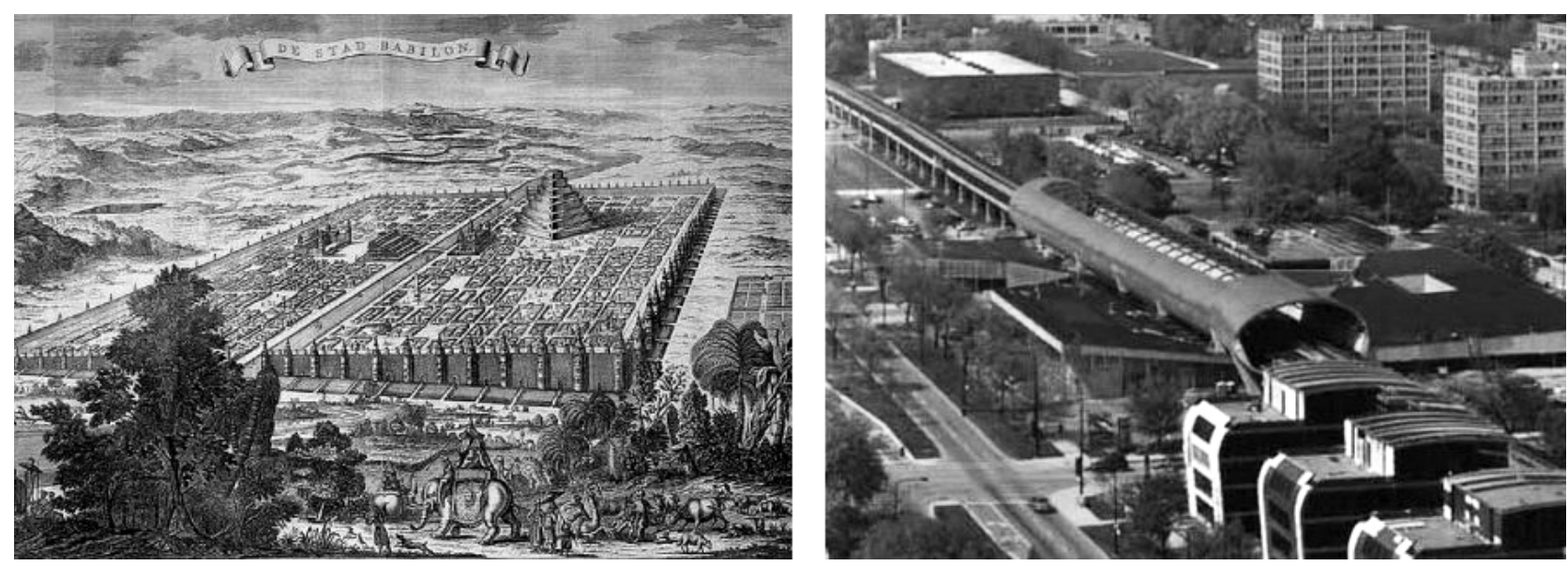

Las nuevas imágenes delirantes de la irracionalidad concreta, tienden a su 'posibilidad' física y real; sobrepasan los dominios de los fantasmas y representaciones 'virtuales' $p$ sicoanalizables. Presentan el carácter evolutivo y productivo característico del hecho sistemático (...). Contra el recuerdo onírico y la simágenes virtuales e imposibles de los estados puramente receptivos 'que sólo se pueden contar', están los hechos fisicos de la irracionalidad 'objetiva' con los cuales ya puede uno herirse realmente. (Dalí 1971: 22-23)

De un modo análogo, Koolhaas apoya su estrategia proyectual en decisiones arbitrarias que adquieren consistencia crítica por su aplicación sistemática en las diferentes fases y escalas de concreción del proyecto, y verosimilitud por la densidad material-fenomenológica de su formalización y puesta en obra.

El principio organizador de su propuesta de concurso es la materialización objetiva de las arbitrarias "líneas de deseo", ${ }^{9}$ itinerarios de los estudiantes -es decir, que emergen en las bases conceptuales del proyecto como un factor ajeno a la voluntad de Koolhaas- en la tierra de nadie que constituía la franja donde se emplazaría el edificio. Al este está la zona residencial del campus, al oeste las facultades. Durante dos días de 1997, un equipo de campo registró estos recorridos, que fueron convertidos en la red de calles e islas interiores del McCormick. El edificio podria haber sido emplazado en otro punto del campus; de hecho, la ubicación propuesta por las bases estaba situado más al sur, en un punto más cercano al Crown Hall, pero el azar objetivo desplazó el foco hacia el norte, activando inopinadamente un objet trouvé: el Commons Building de Mies. Desafía, de este modo, el absurdo de su ubicación en el entorno próximo de la vía elevada, deslizándose bajo ella y parasitándola.
Ya se ha mencionado "el encuentro fortuito...", situación improbable en la que la analogía con la cita de Lautréamont señala una suerte de "belleza"10 y que Koolhaas utiliza como medida de la absurda relación del edificio miesiano con el tren elevado. El "encuentro" -colisión, incluso- irracional de sistemas individualmente coherentes parece haber sido utilizado aquí intensamente como herramienta proyectual, y ello constituye nuestra hipótesis. La formulación programática del encargo habria sido enriquecida con requerimientos de otra indole, que pasarían a formar parte de una matriz cuyos nodos podrian ser recorridos en diferentes itinerarios interpretativos. Conceptualmente, Koolhaas interpone entre nosotros y el McCormick una tupida trama de árboles -la analogía surge espontáneamente frente al conjunto de sistemas estructurales del edificio- en la que las oscilaciones de predominancia interpretativa nos impiden ver con claridad el constructo intelectual que le daria sentido.

En la fase de conceptualización del proyecto, ${ }^{11}$ Koolhaas plantea un conjunto de "sistemas", que abren la posibilidad de lecturas en diversos registros. Cada sistema responde a sus propias reglas de disposición y concreción material, geometría, posición, topología, iluminación, etc. El conjunto se superpone sobre el modelo conceptual del edificio, pudiendo -y ello favorece la ambigüedad interpretativa- un mismo elemento resultar afectado por varios de ellos. En su puesta en obra, la yuxtaposición de sistemas favorece su interacción fenomenológica, dando lugar a un cierto conjunto de percepciones que hacen oscilar la prioridad entre argumentos interpretativos. Se trataría de un juego correspondiente con la ambigüedad de lectura de la obra pictórica de Dalí en aplicación de su método paranoico-crítico. Las dobles o triples lecturas de las imágenes contenidas en
Figura 8. De Stad Babylon. Kircher, Athanasius. 1679. Ref. web 04.

Figura 9. Vista aérea del McCormick T.C.C. desde el SO. Autor desconocido. Fecha desconocida. Ref. web 05 . 


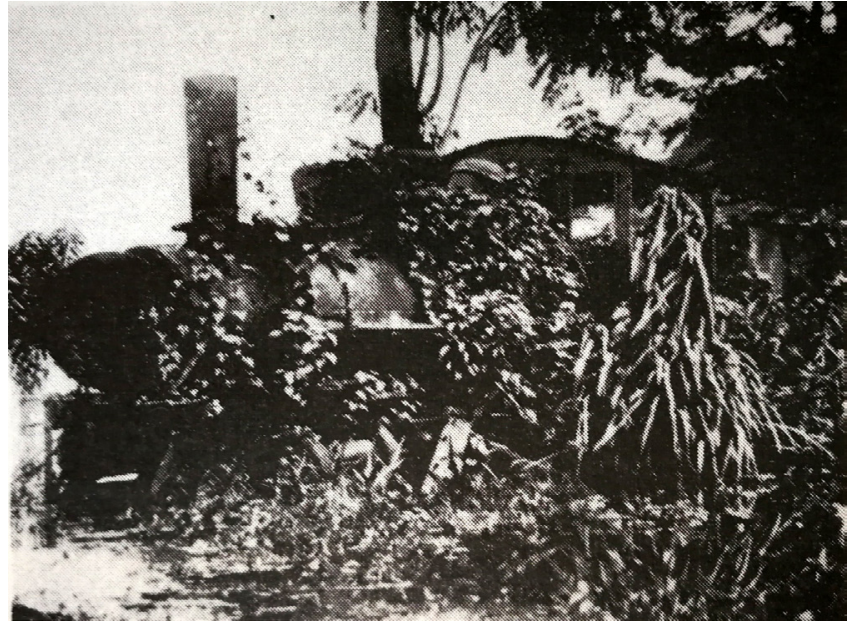

Figura 10. Locomotora potente después de haber sido abandonada durante muchos años al delirio de un bosque virgen. Autor desconocido. Fecha desconocida. AD Profiles 11, 1978: 89.

Figura 11. Interior del edificio bajo el tubo del tren: zona de jue-gos. Baan, Iwan. Fe-cha desconocida. Ref. web 06.

Figura 12. Iluminación proveniente del Panelite naranja. Baan, Iwan. Fecha desconocida. Ref. web 07 . de materiales de uso general en el proyecto. el lienzo tendrían su correlato, en esta hipótesis, por juegos de figura-fondo conceptuales oscilantes, de posiciones de predominancia entre sistemas y de los elementos de un sistema en relación con los otros.

En un conjunto de sistemas así planteado es procedente la renuncia a decisiones preconcebidas respecto a la forma, geometria, estructura, definición espacial o utilización Esas decisiones se presumen contingentes, derivadas de la interacción de los condicionantes impuestos por cada sistema.

El efecto en el usuario de la búsqueda infructuosa de una lógica que dé sentido al conjunto es perturbador, pero la acumulación de estímulos que se le ofrecen -entre los cuales imágenes con gran capacidad connotativa- a los sentidos es excitante. Entre esos polos oscila la experiencia, que los propios alumnos equiparan a "estar en una máquina de pinball"12 y que parece responder bien a la descripción que Dali hace de la actividad paranoico-crítica:

... ya no considera aisladamente los fenómenos e imágenes surrealistas, sino por el contrario, en un conjunto coherente de relaciones sistemáticas y significativas. Contra la actitud pasiva, contemplativa, indiferente y estética de los fenómenos irracionales, está la actitud activa, sistemática, organizadora, cognoscitiva de esos fenómenos considerados como acontecimientos asociativos, parciales, y significativos, en el dominio auténtico de nuestra experiencia inmediata y práctica de la vida. (Dali 1971: 23)

Siempre bajo esta hipótesis, Koolhaas no descarta ni integra: añade y yuxtapone (o superpone). Ello implicaria que en el McCormick no sería presumible una lógica integradora sustentada en la dimensión funcional o de definición espacial, sino otra centrada en la organización de acontecimientos asociativos, parciales y significativos para nuestra experiencia. Ya lo advierte -si se quiere aceptar el juego interpretativo de pensar el McCormick como espacio basura crítico- al sintetizar un aspecto perverso de la modernización como un todo irracional de partes racionales.

Ahora bien, la experiencia percibida por el usuario exige una cierta complicidad en cuanto a la capacidad de reconocimiento o evocación de los conceptos latentes en el juego propuesto. Un factor catalizador de este proceso podría ser el desvelamiento de imágenes fértiles asentadas en la memoria, de mitos, al modo en que eran evocados mediante la práctica provocadora de los surrealistas. En su apropiación del concepto, los mitos son depositarios de invariantes cristalizados en el inconsciente colectivo; verdaderas semillas con potencial para ser reinterpretadas, reforzadas y relanzadas hacia la generación de nuevas imágenes. Uno de los mitos vitales en la experiencia humana -en la propia noción de humanidad- y a su vez matriz generadora de mitos fértiles para los propósitos de los surrealistas es la ciudad.

\section{Mundo Babel}

La fase de conceptualización del proyecto del McCormick utiliza una poética de analo-
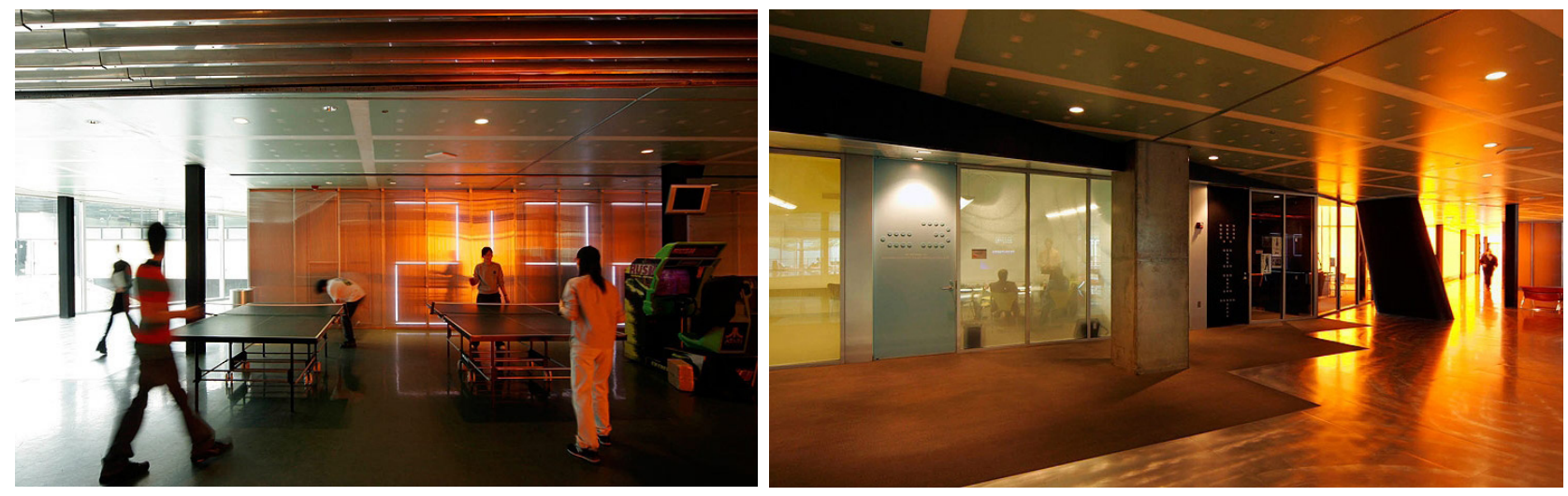
gías afin a la practicada por los surrealistas. El proceso está atravesado por una serie de nombres-imagen que condensan conceptos, tales como "islas", "atajos", "acrópolis", "templo", "bala", "corazón", "cigarrillo", "bucle” o el conocido -por formar parte de los documentos presentados al concurso- de "tapiz pompeyano". ${ }^{13}$ Estos nombres son relevantes porque encapsulan el concepto y preservan su integridad durante el desarrollo de la propuesta de concurso y proporcionan argumentos para su comprensión. El del "tapiz pompeyano", de gran carga connotativa, atrae nuestra atención por su peso relativo en la estrategia proyectual y por su relación con la generación de densidad urbana demandada expresamente en el concurso.

Se puede encontrar en este término, "tapiz pompeyano", una referencia directa a los valores de riqueza espacial de una trama urbana histórica tratados por el ya citado Robert Venturi en una referencia importante para la interpretación del McCormick, Aprendiendo de Las Vegas $^{14}$, pero también en las prácticas de los surrealistas, que entendieron la ciudad ${ }^{15}$ como un palimpsesto de trazas y huellas de hechos, situaciones y personajes cuya presencia latente excitaría la sensibilidad de un paseante atento para estimular el "hasard objectif" ("azar objetivo"), y posibilitan la generación de asociaciones fructíferas. Koolhaas nos indica el camino hacia estas prácticas con un argumento denotativo: el nombre de la trama densificadora de la condición urbana, "tapiz pompeyano".

Una imagen encapsula este concepto, que resulta potenciado con otro de los vectores identificados en el planteamiento programático del proyecto: la diversidad cultural globalizada del alumnado.

El grabado representa la imagen de la ciudad de Babilonia imaginada por Athanasius Kircher. Muestra un recinto amurallado de planta rectangular, atravesado de forma ro- tunda por un cardo que la divide en dos partes. Domina una de ellas la presencia de la Torre. La trama urbana presenta hitos: palacios, plazas adornadas con obeliscos, los Jardines Colgantes...

La ciudad parece asentarse sobre un territorio levemente inclinado, lo que produce el efecto -importante a efectos del somero análisis iconográfico que abordamos- de producir alzados trapezoidales en la muralla, que conserva su coronación horizontal.

Ante esta evocación iconográfica del mito, el término "tapiz pompeyano" adquiere una connotación diferente. Se podría decir que la densa trama de infraestructura que conforma la civitas interpela a la fluctuante e imprevisible urbs que dará sentido a su existencia. El flujo de personas, animales de carga y mercancias que canaliza el eje dominante de la Babilonia mítica es traspuesto al McCormick en un doble flujo superpuesto: el material del tren, que con su ritmo sincopado pauta el tiempo mecánico de la producción con el transporte de personas; y el inmaterial de la información, que fluye en la batería de ordenadores conectados a Internet que ocupan el Broadband, metáfora obligada -por su posición en el eje principal y su disposición bajo rasante- de una infraestructura que ya en ese momento histórico se ha constituido como vital medio de transporte, tanto del conocimiento como de los flujos financieros.

Koolhaas alude al hecho de que "el cuerpo estudiantil es, ahora, literalmente de al menos cuatro o cinco continentes" (Becker 2003). El "purgatorio de mala calidad" producido por la suma de partes que son "fruto de brillantes inventos" tiene su reflejo sobre la tortura infligida a la lengua inglesa descrito en Junkspace. Es verosimil, pues, que un edificio llamado a representar el mundo globalizado acuda al mito de Babel... e incluya un "Hanging Garden". El papel del elemento ausente en el paralelismo establecido por
Figura 13. Efecto del Panelite sobre la visión en el interior del edificio. Baan, Iwan. Fecha desconocida. Ref. web 08

Figura 14. L'evadé (frottage). Ernst, Max. 1926. Ref. web 09.
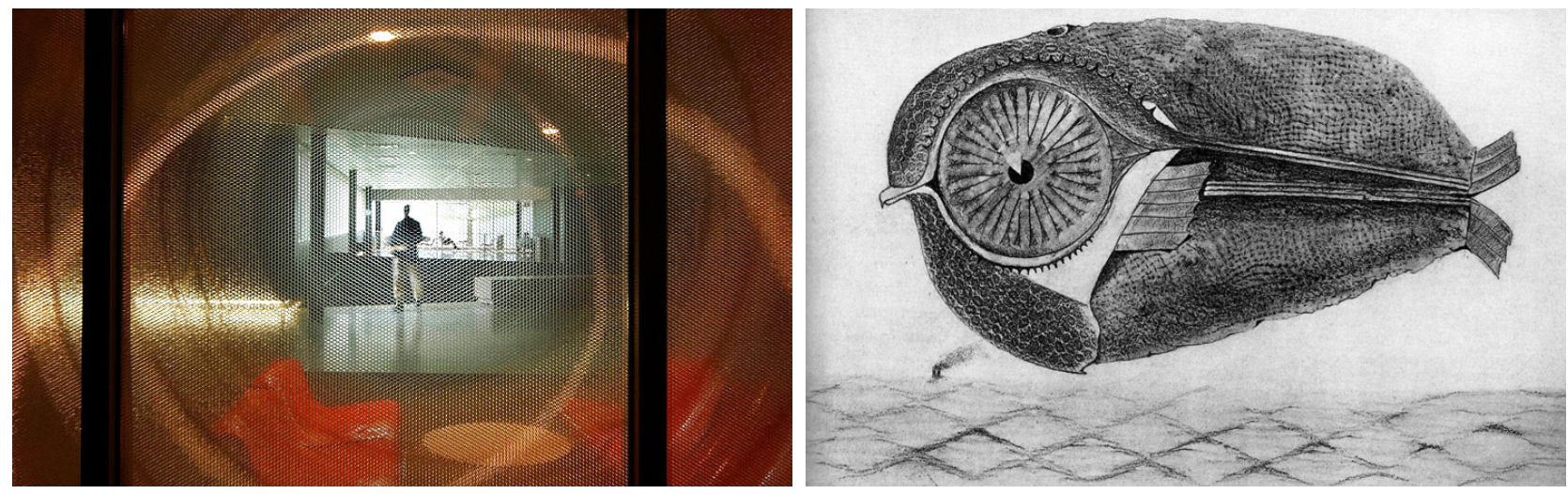
Koolhaas con la triada paraguas/máquina/ mesa de disección generada por Lautréamont es asumido por la potente broma iconográfica de una Babel finisecular.

\section{Un tren y un reloj}

Como queda dicho, la vía del tren marca el eje de la ciudad evocada en el "tapiz pompeyano". Pero en su dimensión iconográfica, constituye un objet trouvé -especialmente provocador y fecundo- dispuesto para recibir una acción transformadora. Según Breton, esta figura cumple en el autor la misma función liberadora que los surrealistas asignaban al sueño: “... libera al individuo de escrúpulos afectivos paralizantes, le reconforta y le hace comprender que el obstáculo que creía insuperable ha sido franqueado" (Breton 1934: 21).

En La crise de l'objet (1928), Breton argumenta que la multiplicación de los objetos cuya utilidad convenida satura "el llamado mundo real" produce una depreciación particularmente propicia para "desencadenar potencias de invención que, al término de cuanto podemos saber del sueño, se hubieran exaltado al contacto con los objetos de origen onírico, verdaderos deseos solidificados". El recurso al tren evoca, por otra parte, las fuentes iconográficas que sirven a Breton para ilustrar su concepto de belleza convulsiva ${ }^{16}$ en el número citado de AD Profiles dedicado a la relación entre arquitectura y surrealismo.

La operación de entubamiento de las vías -en una carcasa estriada de acero inoxidable pulido que aislaría acústicamente el edificio frente al ruido producido por el paso del trense convierte, fenomenológica y simbólicamente, en el argumento principal de la configuración material del edificio. Este dispositivo contiene en su definición primaria un equívoco (un factor añadido de indeterminación): el tren no para sobre el McCormick, contra lo que indica en primera instancia la imagen de una construcción que, apoyando en el suelo, encierra un tramo de vía elevada. ${ }^{17} \mathrm{La}$ decisión se muestra eficaz: La imagen de un tren avanzando sobre una vía en un espacio (visualmente) vacío carece de la intensidad que acumula -por el sentimiento de inminenciala de un tren acercándose a la boca de un túnel o saliendo de él. Así, el entubamiento vela temporalmente la dimensión funcional de la doble vía y abre el camino a la evocación del lienzo de Magritte. La desproporción del tubo respecto al edificio aplastado exacerba el carácter surreal de la imagen y contribuye a hacerla memorable: los estudiantes apodaron de inmediato el edificio como "The Tube".

Además, su peso visual adquiere una dimensión simbólica en el interior del edificio, y proporciona la coartada para forzar operaciones de aplastamiento y fractura del espacio interior en una serie de situaciones espaciales insólitas que, por falta de altura libre, convierten en inaccesibles algunas zonas.

Ya fue mencionada la presencia de $L a$ durée poignardée, cuyo título (La duración apuñalada) alude a un determinado concepto histórico de tiempo, ${ }^{18}$ en el Art Institute de Chicago. ${ }^{19}$ En el McCormick está invertida la posición relativa de la locomotora y el reloj respecto a la representada por Magritte, pero Koolhaas no elude el paralelismo binomial en lo relativo a la medida del tiempo y dispone un reloj digital en la zona de juegos -la más doméstica, por tanto, del edificio- que se encuentra bajo el tubo que envuelve al tren. Opone, sin embargo, el inexorable paso mecánico-electrónico, de naturaleza lumínica, del tiempo reflejado en este reloj, que ocupa toda la altura libre de la planta aplastada por el peso del tren, al tiempo congelado que emana de la luz naranja con la que tiñe el muro cortina de la fachada oeste -y, por tanto, con la que baña todo este ala del McCormick: tiempo cósmico estancado. El conjunto, de una condición intrínsecamente contradictoria, adquiere un carácter onírico, evocador del mundo ambivalente que parece representar Magritte mediante sus dias-noches y sus interiores-exteriores.

\section{Critica por convulsión}

K. Michael Hays fue un miembro relevante del jurado del concurso. Participó con dos ponencias en Beyond Mies, el simposio organizado como "palanca intelectual" del mismo. La primera se centraba en reinterpretar "la obra de Mies como sugerencia de estrategias específicas para enfrentarse a las contradicciones de la sociedad contemporánea", contradicciones que constituyen tema recurrente en la actividad intelectual de Koolhaas; Junkspace riega con vitriolo algunas de las que afectan al mundo construido.

En 1984, Hays atribuía a ciertas obras de Mies un valor que permitía conceptualizarlas bajo la categoria de "Arquitectura crítica": piezas que no responden al modelo cultural dominante, reafirmándolo, ni a la actitud solipsista de una lógica formal autónoma. Ponía como ejemplo tres edificios: los no construidos rascacielos de vidrio triangular y curvo de los primeros años veinte -que en el McCormick sirven a Koolhaas como tema para 
su "Mies Wrap"20 - y, muy especialmente -por haber podido experimentarlo-, el Pabellón de Barcelona de Mies. Según Hays, su definición geométrica no basta para describir la experiencia espacial. La realidad percibida adquiere una dimensión contingente que se define conforme se recorre y experimenta el Pabellón, debido a la elección y disposición de los materiales y el tratamiento de las superficies. La presencia material se desdibuja en transparencias y reflejos que producen una percepción engañosa del objeto arquitectónico. En otras palabras, la experiencia espacial se deriva de un equívoco perceptivo que escapa a la mera comprensión racional de sus elementos delimitadores (Hays 1984).

Existe una analogía entre el efecto que señala Hays y uno de los objetivos declarados por los surrealistas: ampliar el significado de la percepción del mundo más allá de la racionalidad derivada de la mera utilidad, provocando en el espectador situaciones de desconcierto y desrealización. Identificaron temas, imaginaron métodos y llevaron a cabo prácticas que activarian y harian emerger la actividad mental inconsciente -los sueños serian una buena fuente de pulsiones e imágenes-, elevándola a niveles de consciencia. Para romper el ciclo "todo lo que es real es racional, y todo lo que es racional es real"21 alimentaron el concepto de "objeto surrealista", que utilizaba la concreción material del objeto como base para despertar significados latentes agazapados en los objetos familiares, buscando el desencadenamiento de un proceso en el que "lo racional es llamado a reorganizarse sin cesar".

El McCormick produce en buena medida este tipo de experiencia. En su percepción -física y conceptual- la realidad se configura y desconfigura: la perspectiva equívoca derivada de su geometría, la luz contradictoria, las distorsiones topológicas, las imágenes que se descomponen en pixeles que a su vez se configuran como iconos significantes, las superficies reflectantes o coloreadas o lenticulares o polarizantes, las cortinas que representan árboles miesianos cuya silueta se confunde con las sombras de los reales... Todo induce equivocos; la práctica se sitúa muy lejos de la dialéctica que guía el principio operativo miesiano de depuración sintética. Koolhaas pone de manifiesto, exacerbándolas, las "contradicciones de la sociedad contemporánea", que desgrana, en lo tocante a la producción arquitectónica, en Junkspace.

Esta realidad construida presenta rasgos comunes con las acciones favorecedoras de la perplejidad, la desrealización y el azar practicadas por los surrealistas, que reaccionan contra la asunción enraizada en la tradición ilustrada de que lo racional agota la experiencia del mundo y estimulan la emergencia del deseo latente con el fin de enriquecer la experiencia vital. Koolhaas aprecia sus métodos de análisis y conoce sus objetivos, imaginario, medios, y prácticas. Y, por ello, resulta factible su utilización instrumental de los objetivos originales de los surrealistas para emitir, mediante la experiencia que producen, el diagnóstico intelectual que demanda el concurso. Atendiendo al "sindrome" que refleja Junkspace (Becker 2003), podríamos formularla como la imposibilidad de aprehender el mundo construido -"un purgatorio de baja calidad"- bajo parámetros racionales. Koolhaas utilizaria la capacidad de la arquitectura para producir experiencia, y la experiencia para transmitir pensamiento bajo formas alegóricas.

¿Sería, en suma, esta estrategia proyectual, que constituye un intento de representación sintomática -por abstracta que sea- de la situación descrita en Junkspace, calificable como surrealista?

Volvamos a Chicago, en 1986. Eisenman pregunta a Koolhaas:

¿Crees que es posible mantener el surrealismo en un mundo de televisión, un surrealismo total que parece existir fuera del mundo del arte? ¿Crees que es posible mantener el arte a la manera surrealista, o de un modo efectivo, como un discurso artístico? (...) Lo digo muy seriamente. ¿Crees que es posible ser un arquitecto surrealista hoy?

Esta "seria" pregunta de Eisenman complementa a otra que expande un requerimiento del concurso: ¿constituye esta representación -paródica- del "legado de $\mathrm{Mies}^{22}$ haciéndolo extensible al siglo XXI", un dispositivo crítico?

El McCormick Tribune Campus Center, parece responder conjuntamente -a Eisenman y al jurado del concurso- mediante otra pregunta: ¿Es posible trazar una arquitectura que juegue "un papel polémico e ideológico en el último tramo del siglo XX y el principio del XXI" eludiendo la dimensión surrealista?

\section{Notas}

1 Archivo de OMA: Documentación de concurso.

2 Archivo de OMA: Documentación de concurso.

3 En los primeros noventa, Rafael Moneo recurre a una analogía con la obra de Warhol para hacer inteligible a los estudiantes de la Harvard 
Graduate School of Design la estrategia proyectual utilizada por Koolhaas en la materialización de sus proyectos. También menciona la técnica de apropiación extraída de la práctica artística. (Moneo 2004: 315)

4 Hamilton es el autor de "Just what is it that makes today's homes so different, so appealing?", collage de 1956 considerado como pieza fundacional del Pop Art.

5 En una encuesta de 1997, el IIT era considerado el campus más feo de América. En 1998, las matrículas habian caído a 3000 (la mitad que en 1941).

6 Eisenman 1987. Este libro registra los encuentros organizados por la University of Illinois que fueron recogidos en The Chicago Tapes. El comentario incide sobre una alusión indirecta de Michael Graves. También participó Rafael Moneo, quien, visita años después la Villa dall'Ava (París, 1991) y, tras describir su promenade architecturale por la vivienda, concluye: "Todo ello se convierte en marco desde el que "mirar con otros ojos "el mundo en torno". (Moneo 2004: 351)

7 AD Profiles 11, 3-4 1978. Este número dio eco a una gran exposición retrospectiva sobre Dadá y Surrealismo abierta en la londinense Hayward Gallery entre los meses de enero y marzo de ese año.

8 Marcel Duchamp declaraba a James Johnson Sweeney en 1955: "En otras palabras, la pintura no debe afectar sólo a la retina (...); debería estar relacionada con la materia gris de nuestra comprensión, no sólo con lo puramente visual". (Duchamp y Sweeney 1955; traducción nuestra). Tschumi transcribe otra cita: "lo que no me gusta es lo completamente no-conceptual, lo que es puramente retiniano -eso me irrita." (Tschumi 1978: 112; traducción nuestra)

9 Explotación consciente del inconsciente -de los alumnos, en este caso- mediante la fabricación de pruebas fácticas que refrendan y atestiguan la veracidad del delirio, como se describe en DNY la segunda fase del método paranoico-crítico.

10 La apreciación del "Conde de Lautréamont" (Isidore Lucien Ducasse), considerado precursor del surrealismo "bello como el encuentro fortuito, sobre una mesa de disección, de una máquina de coser y un paraguas" configura uno de los rasgos más distintivos del irracionalismo surrealista: la conjunción de realidades inconexas, dislocadas o incluso contradictorias.

11 Archivo de OMA: Documentación de desarrollo del proyecto.

12 "La gente dice que el interior [del McCormick] va a ser como estar dentro de una máquina de pinball”, según la Decana de Arquitectura Donna Robertson. (Becker 2003)

13 Archivo de OMA: Documentación de desarrollo del proyecto.

14 Aprendiendo de Las Vegas, mapa de Giambattista Nolli, La Pianta Grande di Roma, 1748.

15 París fue el escenario principal de sus recorridos experienciales e investigaciones derivadas.

16 Esta imagen anónima publicada en Minotaure, "Locomotora potente después de haber sido abandonada durante muchos años al delirio de un bosque virgen", es reseñada por Dalibor Ve- sely en el citado número 11 de AD Profiles como detonador de la generación del concepto de belleza convulsiva por André Breton: "Aparte del hecho de que el deseo de ver eso ha sido acompañado durante mucho tiempo por un tipo particular de exaltación, me parece que el aspecto ciertamente mágico de este monumento a la victoria y al desastre sería mejor que cualquier otra cosa para determinar las ideas de uno. Puede haber belleza -belleza convulsiva- sólo al precio de la afirmación de la relación recíproca que une un objeto en movimiento con el mismo objeto en reposo". (Vesely 1978: 89)

17 La propuesta de concurso incluía una pasarela peatonal, que discurría entre las dos vías del tren y a su cota, desde la vecina estación 35-Bronzeville-IIT hasta el Campus Center.

$18 \mathrm{El}$ proceso histórico de sincronización global del tiempo horario comenzó con la que impusieron, en el siglo XIX, las necesidades de coordinación para la circulación de los ferrocarriles británicos. (Speranza 2017: 84)

19 Interpelado Magritte respecto a la extraña asociación que representa el cuadro, ilustra el principio operativo de activación surrealista por yuxtaposición imprevisible y brusca de imágenes u objetos heterogéneos: "I decided to paint the image of a locomotive... In order for its mystery to be evoked, another immediately familiar image without mystery -the image of a dining room fireplace- was joined." En otra carta dice: "I thought of joining the locomotive image with the image of a dining room fireplace in a moment of "presence of mind'."

20 El "Mies Wrap" es un artificio dispuesto por Koolhaas para dar respuesta al requerimiento del concurso de incluir un museo virtual de Mies que explicase su legado en un entorno experimental. Se trata de una banda constructiva-conceptual envolvente del edificio que cita diferentes momentos de la obra de Mies: Pabellón de Barcelona, Rascacielos de vidrio, Café Samt und seide, Campus del IIT, Sala de conciertos, Rascacielos genérico y Centro de Convenciones de Chicago,

21 Breton manipula una frase de Hegel: "Lo que es racional es efectivamente real y lo que es efectivamente real es racional".

22 La dimensión surrealista sería interpretable como soporte de la estrategia destinada a poner en valor la obra de Mies, aquejada de la banalización que, inevitablemente, produce la continua visión de lo conocido. En Delirious New York, Koolhaas denomina a este efecto "escasez de realidad".

\section{Bibliografia}

Becker, Lynn. 2003. Oedipus Rem. Chicago Reader 26/09/2003

BREton, André. 1928. Le surréalisme et la peinture. NRF, 1928. Paris: Gallimard.

Breton, André. 1934. Equation de l'objet trouvé. Documents, 34. Bruxelles: Documents.

DALí, Salvador. 1977 (1971). Sí. Barcelona: Ariel.

Duchamp, Marcel y Johnson Sweeney, James. 1958 (1955). Marcel Duchamp. En Nelson, James (ed.). 1958, Conversations with the Elder Wise Men of Our Day. New York: W. W. Norton \& Company. 
Koolhans, Rem y Eisenman, Peter. 1987. The Chicago Tapes. New York: Rizzoli International Publications, Inc..

Gargiani, Roberto. 2008. Rem Koolhaas | OMA. The Construction of Merveilles. Lausanne: EPFL Press.

HaYs, K. Michael. 1984. Critical architecture: Between Culture and Form. Perspecta, 21. New Haven, CT: Yale School of Architecture..

Inch, Peter. 1978. Fantastic Cities. En Vesely, Dalibor (ed.), AD Profiles 11. London: Academy Editions.

IRwin, David. 1966. Pop Art and Surrealism. Studio International 171, 843 .

KoolmaAs, Rem. 2004 (1978). Delirio de Nueva York. Barcelona: Gustavo Gili.

KoolhaAs, Rem y OMA. 1995 (1995). S,M,L,XL. New York: The Monacelli Press.

KoolhaAs, Rem. 2000. Espacio basura. Arquitectura Viva, 74. Madrid: Arquitectura Viva S.L..

KoolhaAs, Rem. 2001. Miestakes. Mies in America. New York: Harry N. Abrams.

Moneo, Rafael. 2004. Inquietud teórica y estrategia proyectual. Barcelona: Actar.

RAmíreZ, Juan Antonio. 1999 (1996). Iconografía e iconología. En Bozal, Valeriano (ed.). 1999 (1996).Historia de las ideas estéticas y de las teorias artísticas, II. Madrid: Visor.

Sмiтh, Peter F. 1978. Architecture, Symbolism and Surrealism. En Vesely, Dalibor (ed.), AD Profiles 11. London: Academy Editions.

Tschumi, Bernard. 1978. Architecture and its Double. En Vesely, Dalibor (ed.), AD Profiles 11. London: Academy Editions.

Venturi, Robert. 2000 (1972). Aprendiendo de Las Vegas. Barcelona: Gustavo Gili.

VESELY, Dalibor. 1978. Surrealism and Architecture. En Vesely, Dalibor (ed.), AD Profiles 11. London: Academy Editions.

KoolhaAs, Rem y Zaera, Alejandro. 1998 (1991). Encontrando libertades: conversaciones con Rem Koolhaas. En El Croquis 53+79. Madrid: El Croquis Editorial. 